\title{
"People count in counting people": A proposed alternative narrative on the origins and history of modern censuses
}

\author{
Antecedents of Censuses from Medieval to Nation States: \\ How Societies and States Count \\ by Rebecca Jean Emigh, Dylan Riley, and Patricia Ahmed \\ New York: Palgrave Macmillan, 2016 \\ ISBN 978-1-137-48502-1 \\ Hardcover US\$110, 266 pp.

\section{Changes in Censuses from Imperialist to Welfare States: How Societies and States Count} \\ by Rebecca Jean Emigh, Dylan Riley, and Patricia Ahmed \\ New York: Palgrave Macmillan, 2016 \\ ISBN 978-1-137-48505-2 \\ Hardcover US\$110, 267 pp.
}

\section{Review essay by Anthony C. Masi ${ }^{1}$}

In the sociology of statistics, there are a few central themes. Desrosières asserts that 18thcentury statistics provided descriptions "of the state, by and for itself," that these descriptions were "suited to their modes of reciprocal interactions" of state and society, and that one "cannot logically separate the state from society" (1998: 147). Further, he comments that official statistics enjoyed the legitimacy of a state institution and represented a "common reference supported by science and technology" (1998: 148). Alonso and Starr note that official statistics "reflect presuppositions about the nature of society" and are "products of social, political, and economic interests that are often in conflict" (1987: 1). Kertzer and Arel argue that while "the state periodically required some assessment of its population for purposes of taxation and conscription", the notion that the "cultural identities of populations mattered in public life was utterly alien to the premodern state" (2002: 2). On a personal note, in teaching a course on "population and society," I like to point out that the concerns of democratic governments are mirrored in the questions (content, modifications, deletions, additions) contained in successive censuses.

1. Professor of Industrial Relations and Organizational Behaviour, Desautels Faculty of Management and Centre on Population Dynamics, McGill University, 1001 Sherbrooke Street West, Montreal, QC, H3A 1G5; email: anthony.masi@mcgill.ca. 
The two reviewed volumes by Emigh, Riley, and Ahmed (abbreviated, respectively, as Antecedents and Changes) address the above issues. They present their work as a direct challenge to a "state-centric" view of official statistics. From their perspective, efficient and effective information gathering requires not only the consent of, but also consultation with, and the willing participation in the process by, the governed. The authors illustrate these points by showing (a) the variety of influences on the content, if not conduct, of censuses and other official statistics, (b) the short-comings of thinking that the state can create useful data without meaningful consultation with other societal actors, (c) the limits of scientific and technical expertise alone in adapting lay categories for incorporation into censuses, and (d) the transformations of statistical systems from "extraction" instruments for taxation to "description" of population composition to "intervention" in the design public policies to accommodate temporally and historically contingent (identity) variables.

Faithful to the titles of the volumes, the authors use medieval and early modern antecedents to and changes in modern censuses to challenge state-centric approaches, to analyse social factors, to document the role that social actors play in determining what, how, and why censuses and official records report results about populations using socially-constructed categories, and to demonstrate the ways in which societal interest-groups influence the development of public policies. Emigh, Riley, and Ahmed formulate a social-constructionist perspective on census-taking. In order to make this counterpoint, however, they set up the point (the state-centric argument) in a stylized fashion, often as a straw dog. Nonetheless, careful reading of these volumes generates new questions and hypotheses about historical and comparative census taking and official statistics for these cases and may be profitably applied in other countries, at different times.

Antecedents starts with a critique of the extant literature and develops the theoretical model. After this exegesis, the empirical focus is on tax collection: Domesday Book in Britain and the Florentine Catasto; the first national censuses: United States, Britain; and regional counting on the yet-to-be-unified Italian peninsula (Lombard Censimento). Changes uses the analytical tools from Antecedents to trace the evolution and development in the censuses of the three areas. Here the narratives emphasize each nation's key issue: class in Britain, race and occupation in the United States, and regionalism (nationalism) in Italy. It also explores how race/ethnicity has been introduced in UK statistics, the use of US counts for civil rights purposes, and the recent concern over immigrant communities in Italy. Each volume has an extensive reference section that across the two books sums to over 75 pages, with remarkably little, and totally justified, overlap.

This is the interactive theoretical model proposed by Emigh, Riley, and Ahmed:

State and social actors, both elite and non-elite, work cooperatively, or in conflict, to gather data about socially constructed categories spanning micro-, meso-, and macro-levels of society, so that the resulting information can be used for extraction from, description of, or intervention on the populations in question.

Diagrams outlining the model are presented early in Antecedents. Table 2.1 ("State-Centered, Society-Centered, and Interactive models of Information Gathering"; p. 42), Figure 2.2 ("Possible Types of Actors, Organizations, and Subdomains"; p. 33) and Figure 2.6 ("Interactive Model of Information Gathering"; p. 39) provide the essence of the state-centric and society-centric models to be tested and the preferred interactive alternative.

To test their theory, the authors develop analytical narratives that trace the path dependent historical patterns from land registration data to census implementation in the three geographical areas: England/Great Britain/United Kingdom, the Italian peninsula/Italy, and colonial America/ United States. This historical sweep is vast: from the Doomsday Book (1086 CE) to the latest full population enumerations (around 2010-11). The theoretical exposition leads to detailed histories 
Masi: Review essay on a proposed alternative narrative for the origins and history of modern censuses

based on secondary source materials of the evolution of early official statistics into modern censuses in three country case studies, but each of the latter is informed by the theoretical model and by the other cases.

For the authors, the primary conclusion of their work is a refutation of the "state-centric" approach: "vibrant censuses" do not depend on the existence of a strong state, as conventional wisdom from the sociology of statistics would have it. Rather, they are generated and used only when and where there is significant interaction between state and society, with ordinary citizens influencing official statistics and having the latter incorporate meaningful "lay categories" into data collection, analysis, and presentation. In short, (some) people count BEFORE they are (appropriately) counted, categorized, and classified.

Emigh, Ripley, and Ahmed illustrate these points by showing why social class in the UK, race and ethnicity in the USA, and region in Italy play such significant roles in each country's official statistics. The authors are practitioners of the "hit them early, hit them often, and hit them hard" school of academic writing. They elaborate, illustrate, argue forcefully, and then return to the claim that their theory and analyses overcome five major shortcomings of state-centric approaches: (1) exaggeration of the correlation between state power and information gathering: strong states do not always produce more information than weak ones; (2) misunderstanding of the state's inability to impose categories and extract new information: the importance of lay categories and "common sense"; (3) overstatement of the role of state bureaucrats in designing and implementing census: census intellectuals often fail when they ignore the lay categories; (4) forgetting the power of social actors to influence information gathering: struggles over what to collect are not always won by the state; and (5) miscalculation of the extent to which the state's goals and intentions can drive data collection: historical trajectories can constrain as well as enable (Antecedents, p. 11-12, 15-16).

At the end of Changes (p. 218-22), the conclusions are re-proposed: (1) the form and intensity of state-society interactions regarding censuses (and other official statistics) change in non-linear ways over time; (2) the state bureaucracy responsible for collecting, analyzing, and disseminating official statistics needs to interact with its publics to maintain its legitimacy; (3) methodological techniques and practices generate little interest unless they also animate social conflicts and the political participation that stimulate the evolution of census taking; (4) in the interaction between state and society in generating official statistics, far too little attention has been paid to social factors; (5) the purpose and timing of data gathering efforts influence state-society interactions; and (6) in the bottom-up approach, ordinary people play a significant role in census efforts, along with bureaucrats and elites. Stated differently, information gathering depends on state-society interactions; social actors including non-elites, with varying levels of influence, can lead information gathering; and their influence is strongest when states have developed and routinized information gathering efforts.

The authors offer "empirical implications" for future research: employ an appropriate tool in the evaluation of state strength; make sure you understand the "lay categories," i.e., commonsense classifications used by members of that society; assess the value added by "information intellectuals" in that society; explore the power dynamics among the social actors, elites, census intellectuals, and non-elites; and trace out the "historical trajectory" of processes in the case at hand, in order to appreciate its path dependency.

Consider these illustrations, which, in the assessment of the authors, falsify the state-centric hypothesis of a positive correlation between state strength and data quality/quantity. In the 15th century, facing a centralized and strong state, English lords were nonetheless able to resist providing tax-relevant information and/or having it recorded, while landlords on the fragmented Italian peninsula complied with requests to provide sufficient information for their city-states to generate 
appropriate revenues. Indeed, the weak states on the Italian peninsula collected and used nominative information and had much more detailed data on land holdings that strong-state England, which was barely able to get an accurate head count. By the end of the 18th century, the newly established American federal republic, a weak state, used its constitution to link taxation and political representation by requiring what is considered the first truly modern census - based on individual enumeration, universal coverage within its territory, simultaneity of information gathering, and with a defined periodicity of ten years.

However, in the UK, given that the landlords could block desired state action and because of the pre-existing and emerging class divisions that pitched peasants, labourers, capitalists, and landowners against each other, might that not indicate that it was a "weak state"? In other words, has state strength been appropriately operationalized in this case?

On the importance of participatory inclusion in the development of categories and classifications, the contrast between Italy and the USA is emphasized. Record-keeping systems in both countries were, and remain, somewhat fragmented. However, the professional isolation of Italy's National Institute of Statistics (ISTAT) as compared to the publicly visible and engaged US Bureau of the Census (Department of Commerce) means that the latter is better positioned to produce meaningful statistics and a "vibrant" census. In the United States, the intense interactions surrounding the census, from its role in apportioning seats in the House of Representatives to its role in helping people identify with their particular group of choice, the institution is indeed "vibrant" because of the input it gets from the public_-but also because it is very accountable to that public, as well. In Italy, social interaction between census takers and the public is virtually absent, so that country's census has become "an annoyance" (Changes, p. 199).

A distinction should be made between deciding what will be included and determining how to actually conduct the census. The authors do not question that a state apparatus is necessary to conduct a technically accurate census. Italy was first in collecting and reporting nominative data in its cadastral systems. England had its once-off Doomsday Book, which only indicated "usage rights," while the Italian city-states ongoing cadastral records were integrated into a highly "marketized" environment. Looking at history from this perspective does call into question the roles of lord and peasant in the great transformation. Only later did states and citizens figure out the benefits of combining attributes into statistical tables. Here, the authors are on track in concluding that data collection infrastructure does not determine the content of census, nor even drive the process that makes such a determination. However, these arguments of a "push from below" in terms of categories and classifications clearly require participatory (democratic) structures.

Antecedents and Changes use censuses to illustrate processes of social change; they do not address the technical aspects of information gathering, diffusion through international associations and accords, nor how such things can have an impact on the conduct of modern censuses. That story probably contains more convergence than path dependence. It would be interesting to apply the interactive framework proposed by the authors, in terms of "instrument of social scientific public policy" (Changes, p. 21), to assess the very different trajectories of two transitions from interventionist long-form censuses to survey instruments: the relatively successful 2010 US "American Community Survey" and the dramatic Canadian flip-flop between 2011 and 2016 of its "National Household Survey."

In Antecedents (p. 11), the authors argue that the validity of the state-centric approach necessitates a strong positive correlation between state power and information gathering, i.e., powerful states gather the most information and are best at census taking. In addition, these states must also develop new categories and classifications, and not just incorporate those from society. Finally, census bureaucrats rather than information intellectuals play the principal role in developing cen- 
sus design, questions, and dissemination of results. But do strong states even need censuses to take certain actions or govern in a given way? Should the state-society dichotomy be expanded to a state-science-society trichotomy?

An important function of a census is to provide the size of the population in a given area at a given time. If an earlier enumeration is also available, we can estimate growth. In looking at the three cases chosen for inclusion in Antecedents and Changes, it is clear that the starting points are far from equal, and that the changes characterizing them over time are dramatically different. Do these starting points and trajectories carry significant implications for the validity of the model or the empirical analyses presented by the authors?

The two volumes need to be read together; indeed, the logical structure is that of a single book. The split does lead to some repetition. I found that reading each country case across the two volumes provided more coherence to the arguments than the strictly period-based division used to separate them. The qualitative comparisons between the three country case studies are informative and entertaining reading. On theory, however, there is some heavy going. At one point I wished for an "old-style" format, with a tightly-knit main body for the points and pages of detailed footnotes with the counterpoints, instead of having to read the argument and its counter sequentially.

Returning to the quotations in the first paragraph of this review essay, the social constructivist perspective on antecedent to and changes in modern censuses rests on a stylized characterization of state-centric perspectives and may not be as dramatically different from the mainstream interpretation as Emigh, Ripley, and Ahmed claim it to be. The historical details and the comparisons produce ample thought-provoking insights. These carefully detailed historical reconstructions of the three case studies are first-rate and are worthy of attention by sociologists, demographers, and others interested in official statistics, especially censuses.

\section{References}

Alonso, W., and P. Starr (eds.). 1987. Introduction. The Politics of Numbers. New York: Russell Sage Foundation.

Desrosières, A. 1998. The Politics of Large Numbers: A History of Statistical Reasoning. Cambridge, MA: Harvard University Press.

Kertzer, D.I., and D. Arel. 2002. Censuses, identity formation, and the struggle for political power, in Census and Identity: The Politics of Race, Ethnicity, and Language in National Censuses. Cambridge (UK): Cambridge University Press. 